\title{
BACTERIAL BIOFILM DEVELOPMENT ON HYDROXYAPATITE-COATED GLASS
}

\section{Aim}

Evaluate hydroxyapatite-coated glass as an alternative substratum for modeling primary colonisation of the tooth surface by Streptococcus sanguis.

\section{Introduction}

Glass plates are frequently used as the substratum in flow cell experiments to allow the continuous observation of biofilm development by microscopy. Though other materials may be preferred for their surface properties, glass is likely to be chosen for convenience and optical clarity. Many workers have used glass as a substratum for investigating adhesion of bacteria to the tooth surface, despite it's relatively high surface free energy and different chemical composition compared to dental enamel. Coating glass with hydroxyapatite, the mineral component of dental enamel, may provide a more biologically relevant substratum than glass, whilst retaining the convenience of glass plates in flow cell experiments.

\section{Materials and Methods}

Flow Cell, organisms, and media

Glass plates were magnetron sputter-coated with hydroxyapatite (by Plasma Biotal Ltd., UK), producing a thin transparent layer. Coated or uncoated plates were assembled into a flow cell (Figure 1) as described previously by Morgan and Wilson (2000). The assembled flow cell formed a chamber $0.6 \mathrm{~mm}$ deep and $38 \mathrm{~mm}$ wide, through which a mucin containing artificial saliva (Pratten et al., 1998) was pumped to achieve a shear rate of $13.0 \mathrm{~s}^{-1}$ (mean velocity $1.2 \mathrm{~cm} \mathrm{~s}^{-1}$ ). The growth medium was inoculated with an overnight culture of $S$. sanguis at the beginning of each experiment, as if the bacteria were present in the saliva after tooth brushing. The batch kinetics of the feed culture were measured by optical density (Figure 2) and viable count (not shown)

\section{Time lapse analysis}

S. sanguis biofilm development was observed using a 32x objective lens and images were captured at five minute intervals by a CCD camera attached to the microscope. Images representing $0.025 \mathrm{~mm}^{2}$ of the surface, were analysed to determine the percentage coverage of the substratum over 24 hours. Removal of biofilm was also assessed by gradually increasing the shear rate to a maximum of 52.5 $\mathrm{s}^{-1}$ (mean velocity $4.6 \mathrm{~cm} \mathrm{~s}^{-1}$ )

\section{Statistical analyses}

At least four separate experiments were performed for each material, and the mean percentage coverage for each hour was calculated. The means were compared using hierarchical repeated measures analysis of variance.

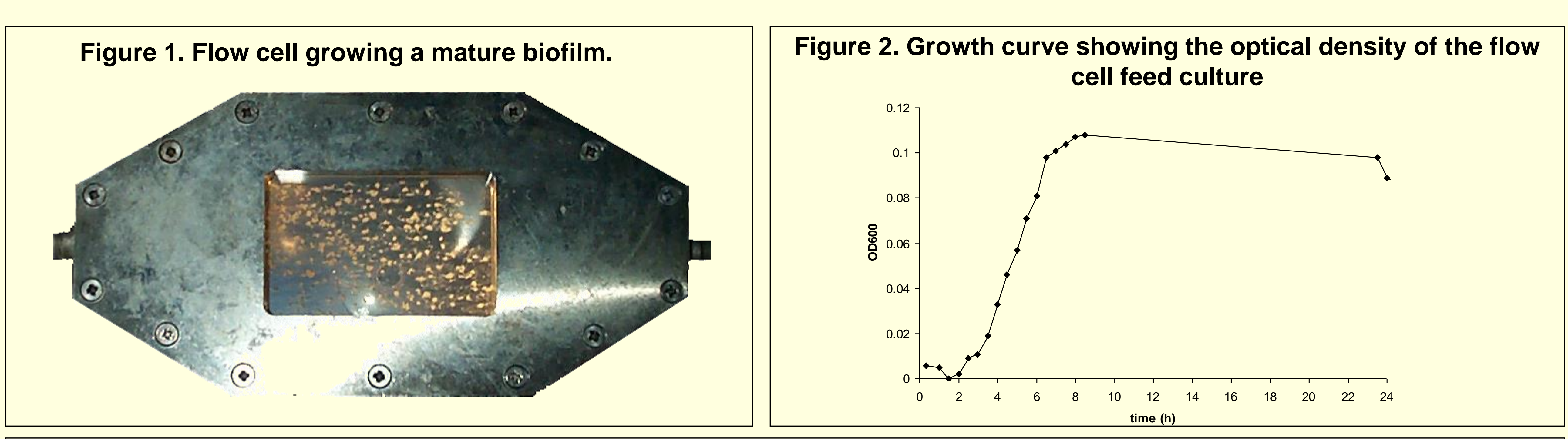

Figure 3. Example images used for surface coverage analysis, showing $S$. sanguis biofilms developing over 24 hours on plain

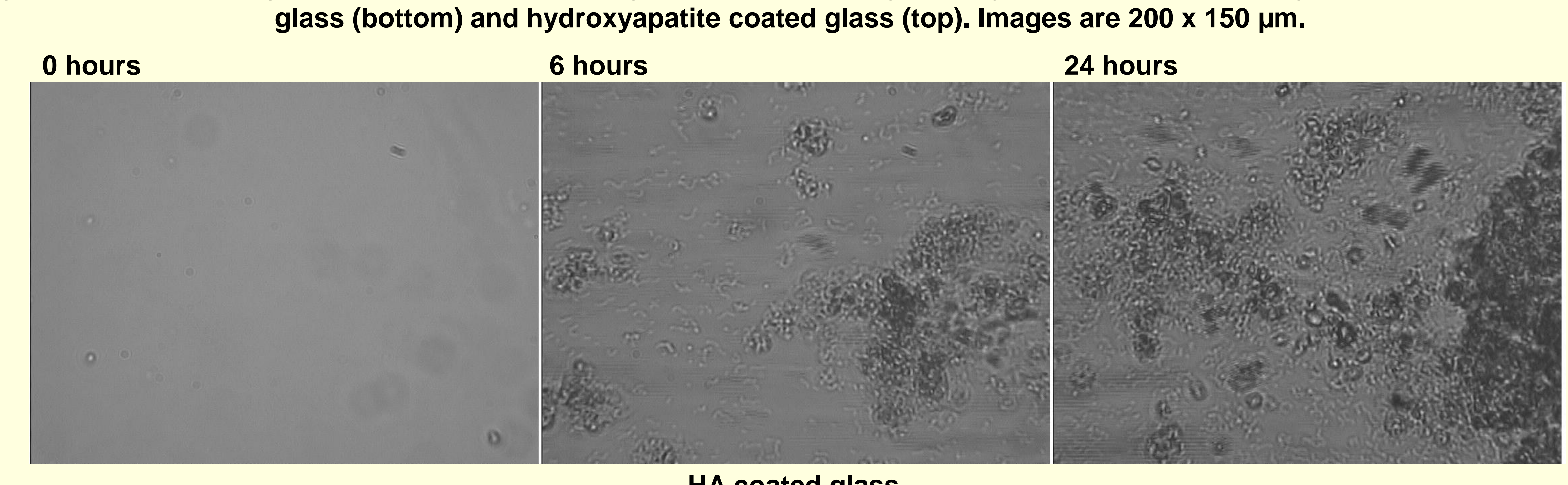

HA coated glass

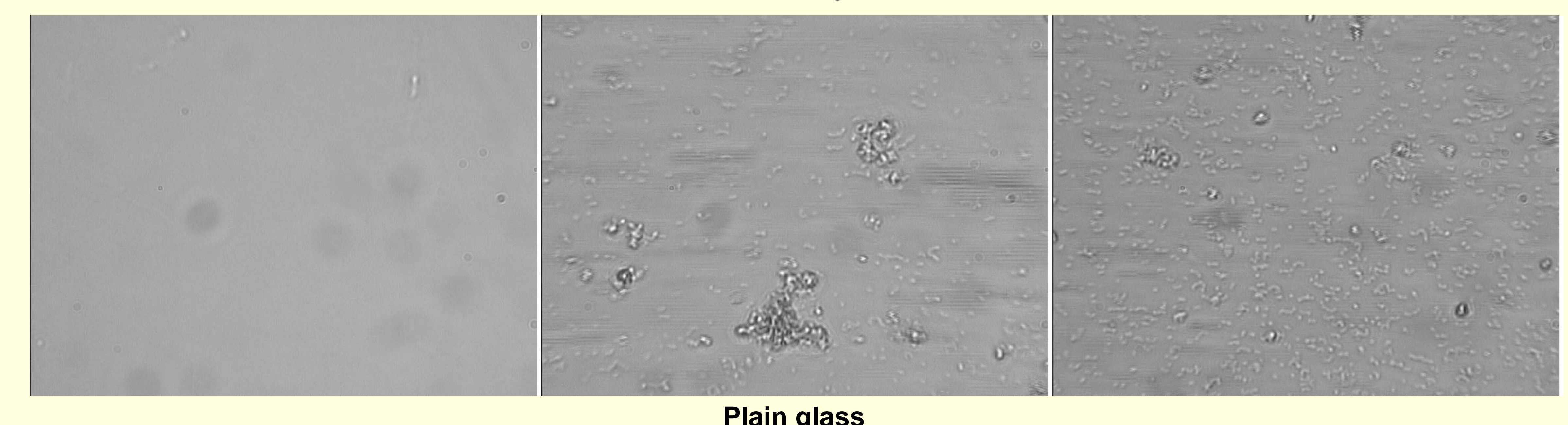
Figure 4. Surface coverage of $S$. sanguis biofilm on plain glass and hydroxyapatite coated glass in a flow cell fed with artificial
Glass

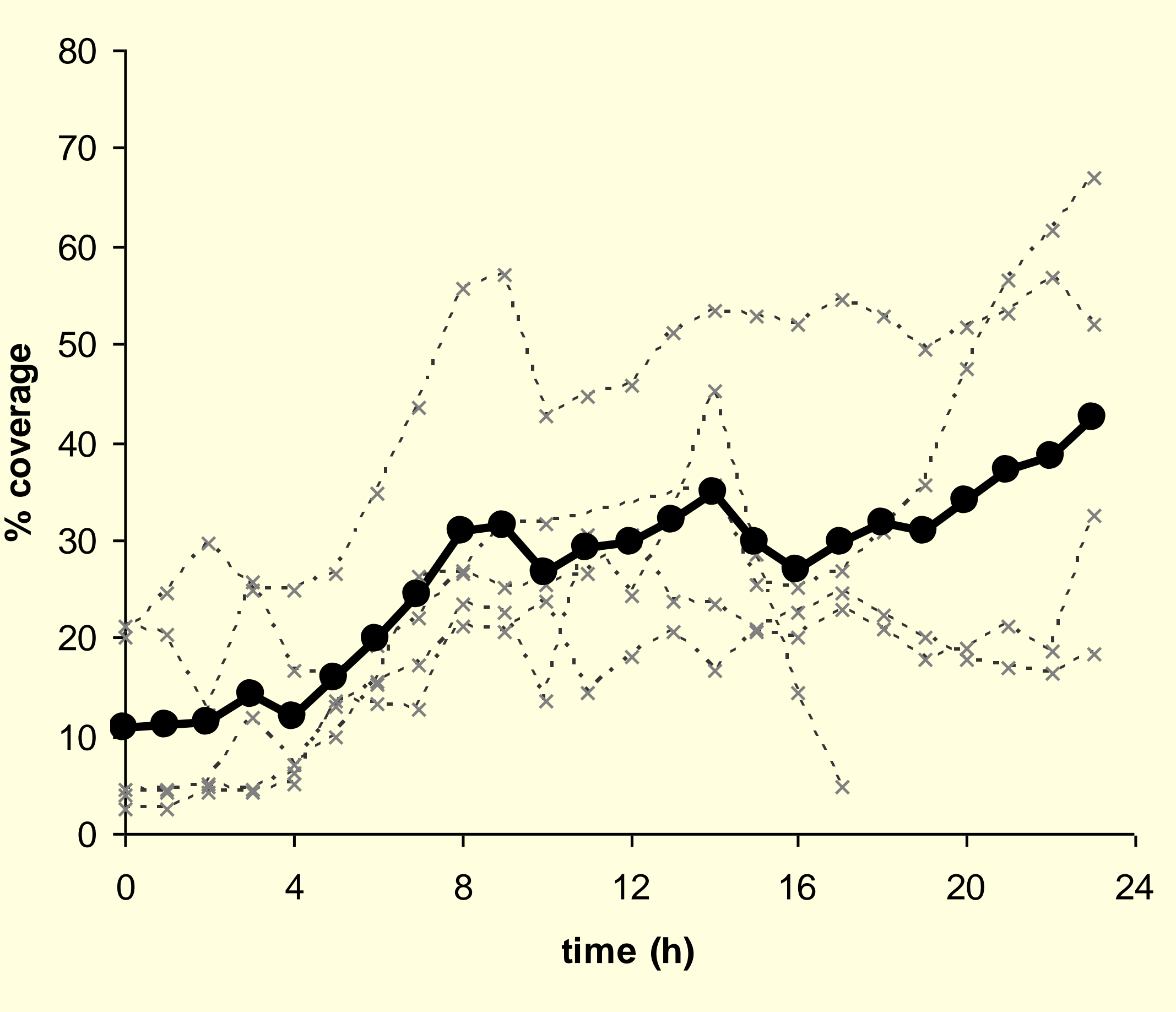

\section{Results}

For both substratum materials, image analysis showed a significant $(P<0.001)$ increase in attached cells during steady flow at a shear rate of $13.0 \mathrm{~s}^{-1}$ (Figure 4). After 24 hours approximately $40 \%$ of the glass surface was covered whilst only $20 \%$ of the hydroxyapatite surface was covered, however this difference was not statistically significant $(P=0.192)$. Increasing the shear rate gradually to $52.5 \mathrm{~s}^{-1}$ (mean velocity $4.6 \mathrm{~cm} \mathrm{~s}^{-1}$ ) over 90 minutes did not significantly reduce biofilm coverage on either material (data not shown). The feed culture lag phase lasted for approximately two hours, followed by an exponential phase for approximately four hours before the onset of stationary phase (Figure 2). Example images used for analysis are shown in Figure 3.

\section{Discussion}

S. sanguis formed biofilms on plain glass and on hydroxyapatite-coated glass in the flow cell. Image analysis was used to compare the accumulation of bacteria on the surfaces but it was not possible to demonstrate a statistically significant difference between the two materials. Any real differences in biofilm formation between the materials may have been masked by the high variability of data between experiments. This variability was largely a result of biofilm heterogeneity combined with a small field of view, and could therefore be reduced by taking more replicates. Differences between the surfaces may also have been reduced by the adsorption of a conditioning film to the surface.

The feed culture kinetics were approximately duplicated by the surface coverage kinetics, except that the biofilm lagged behind the feed culture by about two hours. A similar pattern has been previously observed for Pseudomonas aeruginosa biofilms in a flow cell (Rice et al., 2000). This lag may be caused by cells being in a planktonic phenotype during exponential growth, and switching to a biofilm phenotype as nutrients in the medium become depleted.

\section{Conclusions}

Hydroxyapatite coated glass can easily be employed in flow cell experiments

S. sanguis biofilm forms at a similar rate on plain glass and coated glass

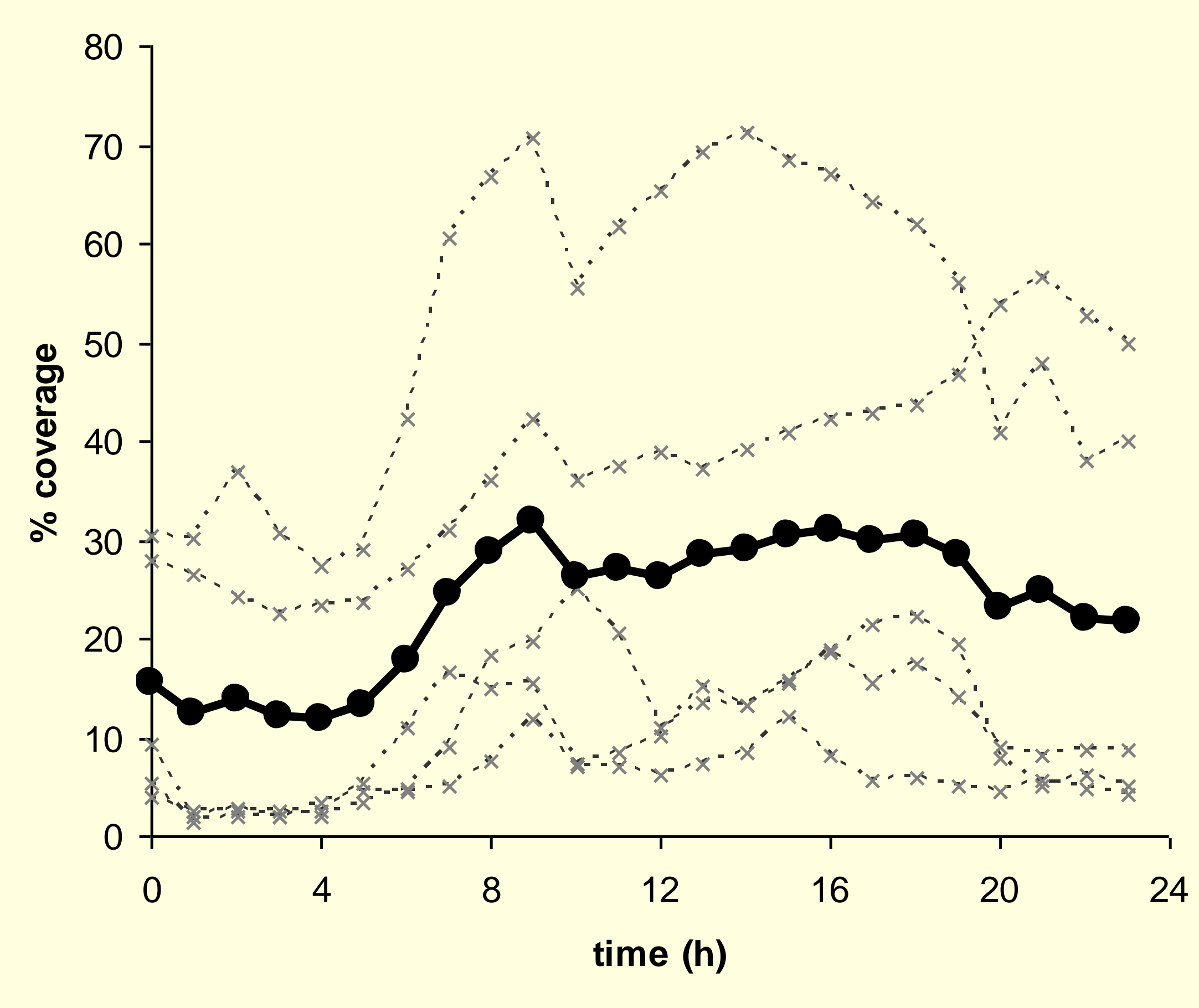

Differences in surface properties may be masked by the development of conditioning film

Accumulation of biofilm exhibited a lag phase of approximately four hours

Acknowledgements

This work was supported by Procter and Gamble Technical Centres Ltd.

References

Morgan TD, Wilson M, 2000. Anti-adhest
cleanser. J. Appl. Microbiol. 89: 617-623. containing mouthwasses on the formation and viability of Streptococcus sanguis biofilms. J. Appl.
Microbiol. 84, 1149-1155. Rice AR, Hamilton MA, Camper AK, 2000. Apparent surface associated lag time in growth of
primary biofilm cells. Microb. Ecol. $40,8-15$. 